\title{
RESPONSABILIDADE CIVIL NO NOVO CÓDIGO CIVIL BRASILEIRO
}

\author{
MisAel Montenegro FilHO*
}

\begin{abstract}
1 - A perspectiva de mudança; 2 - Modificações antevistas na matéria de responsabilidade civil; 3 - Conclusão; 4 - Referências
\end{abstract}

\section{I- A perspectiva de mudança}

A perspectiva de mudança da lei civil, talvez a lei mais importante do nosso ordenamento jurídico depois da Constituição Federal, determinou a redação deste singelo trabalho, que tem como principal objetivo discutir, de forma preliminar e superficial, as modificações que são antevistas na lei em destaque, na parte relativa à responsabilidade civil.

Escrever sobre o assunto, neste momento, causa na minha pessoa uma certa perplexidade, porque estamos na verdade realizando um teste de futurologia, uma adivinhação do que está por vir, tudo considerando que a formatação da lei apenas pode ser medida quando a mesma for efetivamente aplicada. Neste momento - o da aplicação - é que saberemos se a lei se presta ou não ao alcance de seus fins.

Escrevo este trabalho guiado e inspirado nas lições do saudoso jurista Mário Moacyr Porto, quando asseverou que "A Casa do Direito, como a casa de Deus, tem muitas moradas. mas não há lugar em nenhuma delas para os débeis de vontade $\mathrm{e}$ os fracos de coração."

É inspirado em lições como essa que me debruço na análise das modificações que são antevistas na matéria relativa à responsabilidade civil.

E ao analisar o NOVO CÓDIGO CIVIL BRASILEIRO, indispensável se fazer um comparativo entre legalidade e Justiça, concluindo-se, sem qualquer sombra de

I O tema tratado neste artigo foi objeto de palestra proferida pelo seu autor durante congresso jurídico a respeito do novo Código Civil Brasileiro. realizado em abril de 2001 no Auditório do TRIBUNAL REGIONAL FEDERAL DA $5^{a}$ REGIĀO.

* Professor de Prática Jurídica Cível da ESMAPE. Advogado, consultor internacional da USAID, da FAO e do Land Tenure Center, da Universidade de Wisconsin - Madison.

R. Dir. Adm.,

Rio de Janeiro, 229: 115-123.

Jul./Set. 2002 
dúvidas, que muitas vezes há um desencontro manifesto entre estas idéias. Exemplo trazido pelo ínclito jurista e Professor Celso Antônio Bandeira de Melo denota a injustiça que se observava na faculdade dada ao senhor feudal de manter relação íntima, vale dizer relação sexual, com as noivas dos servos da gleba.

O direito à adoção daquele procedimento era garantido do ponto de vista legal, mas injusto, pelo menos em relação aos servos da gleba. Em outras palavras, podemos dizer que a legalidade, em algumas situações, opera e traz a injustiça como conseqüência.

As perguntas que são feitas neste momento são as seguintes:

a) será que o NOVO CÓDIGO CIVIL BRASILEIRO semeará injustiças no meio social, afastando-se e contrapondo-se às práticas vivenciadas pela população de um modo geral?

b) será que o legislador redigiu codificação que se destinaria a uma casta social específica, ou teria previsto normas em prol de toda a população?

Estas perguntas derivam do descrédito da população em relação ao Congresso Nacional. E quando me refiro a descrédito, não me apoio em recentes fatos havidos no seio daquela instituição, que acabaram por determinar o afastamento de parlamentares que teriam se comportado com falta de decoro, mas sim em algumas atuações legislativas do Congresso no passado, a respeito de matéria jurídica.

Basta citar que a maioria esmagadora das emendas constitucionais; reformando a Carta Magna, foram aprovadas em benefício do capital externo, sem se voltarem à população, nenhuma delas em benefício da idéia de Justiça social.

O discurso não é político, como poderia parecer, mas preparatório de divagações jurídicas que vou agitar, apenas sinalizando, neste momento introdutório, que as modificações são sempre vistas com descrédito, com desconfiança, pelo menos na fase inicial de avaliação, presumindo-se ou pressupondo-se que teriam sido articuladas e projetadas em proveito de uma minoria, mais uma vez afastando os desejos da maioria.

Entendo, contudo, que devemos nos despir dessa predisposição de concluir, de forma apressada, que o NOVO CÓDIGO CIVIL teria essas características teratológicas antes referidas. Muito fácil, neste momento, seria adotar a posição de arquiteto de obra pronta, aquele que muito sabe criticar, mas pouco ou nada sabe construir.

Estamos agora discutindo uma legislação recentemente aprovada, mas que deverá vigir por anos e anos a fio, por décadas, talvez por mais de um século. E até o último dia de sua aplicação, vejam, desse Código que sequer ainda vige no mundo do Direito, surgirão dúvidas e divergências de interpretações.

O Direito é isto; é divergência, é questionamento, é o desejo de afastar a postura mecânica e física daquele que baixa a cabeça para apenas concordar com tudo o que Ihe é dito. Como já asseverou Betrand Russel, em expressão reproduzida pelo Relator do Projeto do Código Civil, "Encontrarás mais prazer na divergência inteligente do que na concordância passiva." 
O Código atual, embora em vigor desde o ano de 1916, ou seja, há mais de 85 (oitenta e cinco) anos, apresenta artigos que estão em ápice de discussão pretoriana exatamente nos dias atuais, revelando a aplicabilidade da máxima do Relator do Projeto do Código aprovado, de que "as leis dirigem-se preponderantemente ao futuro."

Apenas para ilustrar, cito o art. 1.483 do atual Código, dispondo que "A fiança dar-se-á por escrito, e não admite interpretação extensiva."

Transpondo dito preceito para a realidade inquilinária, verificamos o agitado debate pretoriano a respeito da vinculação ou não do fiador a contratos de locação automaticamente renovados, findo o prazo de vigência do primeiro ajuste.

A questão foi tão debatida em época recente, apesar do Código datar de 1916, que resultou na edição da Súmula de $n^{\circ} 214$ do STJ, indicando, ipsis literis, que "O fiador na locação não responde por obrigações resultantes de aditamento ao qual não anuiu."

O exame é singelo, mas serve apenas para demonstrar que o que estamos discutindo será revisitado todos os dias nos próximos $10,20,30,50$ ou talvez 100 anos. A discussão é portanto nobre, sadia e deve ser bem aceita.

Mas vamos à análise do ponto específico, ou seja, das modificações na matéria da responsabilidade civil.

\section{2 - Modificações antevistas na matéria de Responsabilidade Civil}

O cotejo entre o atual CÓDIGO CIVIL e o Código recentemente aprovado trouxe à minha pessoa contentamento, em grande parte da análise, mas algumas preocupações. Como sou adepto de ouvir primeiro a notícia ruim para depois escutar a boa, na tentativa de preservar somente a última lembrança, começo pelas preocupações, que não são muitas.

A primeira delas diz respeito à interpretação do art. $950^{2}$ do NOVO CÓDIGO CIVIL BRASILEIRO. Este preceito refere-se à reparação no caso da ofensa, vale dizer, do ato do agente, que causa defeito em relação ao ofendido, defeito este que impeça o exercício de atividade profissional, ou lhe diminua a capacidade laborativa.

A redação dada ao dispositivo em tela praticamente repete o que se encontra previsto no art. 1549 do atual Código Civil. Mas o problema, a meu ver, não se encontra no caput do artigo enfocado, mais precisamente do art. 950 do NOVO CÓDIGO CIVIL.

2 Apenas para que seja firmado o raciocinio lógico das colocaçōes feitas, transcrevo o artigo em destaque: "Art. 950. Se da ofensa resultar defeito pelo qual o ofendido não possa exercer o seu ofício ou profissão, ou se lhe diminua a capacidade de trabalho, a indenização, além das despesas do tratamento e lucros cessantes até o fim da convalescença, incluirá pensão correspondente à importância do trabalho para que se inabilitou, ou da depreciação que ele sofreu." 
O problema é vislumbrado através da análise do parágrafo único deste artigo, estipulando. de forma inovadora, que "o prejudicado. se preferir, poderá exigir que a indenização seja arbitrada e paga de uma só vez."

Vale dizer que numa situação de atropelamento, em que a vítima suportou despesas de tratamento no importe de $\mathrm{RS} 1.000,00$ (um mil reais). vítima esta que se encontrava com 25 (vinte e cinco) anos na data do fato, que perdeu membro inferior e que auferia renda de 02 (dois) salários mínimos por mês, poderá, além dos RS 1.000,00 (um mil reais) antes citados, exigir que o ofensor lhe pague algo em torno de $\mathrm{R} \$ 200.000,00$ (duzentos mil reais), que corresponde à multiplicação do salário da vítima pelo número de meses compreendidos entre a data do fato e a data em que a vítima completaria 70 (setenta) anos de idade. estimada como idade média do cidadão brasileiro.

Esta obrigação já existia, respeitando-se o princípio de reparação total em favor da vítima: a inovação diz respeito à possibilidade do prejudicado exigir que a indenização seja arbitrada e paga de uma só vez.

Vejo o problema sob dois aspectos. um de ordem legal e outro de ordem natural e financeira. O primeiro, de ordem legal, surge da constatação de que o art. 602 do Código de Processo Civil prevê regra impositiva, determinando ao magistrado, diante de hipótese de indenização por ato ilícito relativa à prestação de alimentos, que condene o devedor a constituir um capital que assegure o cabal cumprimento da obrigação.

Este capital, representado por imóveis ou títulos da dívida pública, poderá ser substituído pela prestação de caução fidejussória.

Como visto, estamos diante de um impasse. de um conflito legislativo, no meu modesto entender. De um lado a lei processual afasta o pagamento da indenização de uma única vez, determinando a constituição de uma garantia; de outro a lei civil determina que a indenização, se assim for requerido pelo ofendido (e lógico o será em todas as situações), seja quitada de uma única vez.

Qual das duas normas deveria prevalecer. no anseio de um sistema jurídico que seja harmonioso? Afrontando a minha própria formação e princípios, que sempre se inclina ou tende a se inclinar para tutelar os interesses de vítimas de atos ilícitos, ouso em afirmar, com lamentações, que a norma a prevalecer é a do art. 602 do CPC, e explico as razões desta conclusão.

Entendo que a discussão em tela não se refere nais ao direito da parte de obter ou não a reparação; já havendo sido deferida essa pretensão através de prévio processo de conhecimento.

O que estamos aqui falando é da materialização da condenação, vale dizer, de questões processuais. A inteligência do parágrafo único do art. 950 do NOVO CÓDIGO CIVIL BRASILEIRO denota que estamos falando de pagamento, que é exatamente a materialização de uma indenização que foi anteriormente arbitrada.

Estamos, portanto, falando de execução da sentença, do julgado que constituiu o direito ao recebimento da indenização, incluindo-se alimentos em favor do vitimado. A análise da situação topográfica do art. 602 do CPC revela que o mesmo está inserido no LIVRO II daquela codificação, relativo ao PROCESSO DE EXECUÇÃO. 
Se a norma, determinando o pagamento da indenização de uma só vez ou mediante a constituição de capital, é de natureza processual. obrigatória a aplicação do art. 620 do Código de Processo Civil, que dispõe "Quando por vários meios o credor puder promover a execução, o juiz mandará que se faça pelo modo menos gravoso para o devedor."

Parece, pelo menos aos meus olhos. que é menos gravoso ao devedor constituir capital do que se ver compelido a efetuar o pagamento da indenização de uma única vez. Vejam que o exemplo utilizado no início como premissa - o do atropelamento - retrata um pensionamento módico, de apenas 02 (dois) salários mínimos por mês.

E se a vítima fosse um advogado com 30 (trinta) anos de idade, que, em decorrência do acidente, perdeu seus membros superiores e que auferia uma renda mensal de $\mathrm{R} \$ 5.000,00$ (cinco mil reais). Neste caso, a indenização, cujo pagamento poderia ser exigido de pronto, seria de aproximadamente $R \$ 2.400 .000,00$ (dois milhōes e quatrocentos mil reais).

$O$ outro argumento que me faz concluir pela prevalência da norma processual origina-se de considerações de ordem natural e financeira. A parcela que se pretende receber corresponde à pensão mensal. ou seja, uma importância igual à auferida pela vítima antes da ocorrência do fato. É uma espécie de retorno ao status quo ante, assegurando ao prejudicado receber do infrator a mesma importância que se originava do trabalho da vítima.

Se o recebimento do salário. ou dos rendimentos da vítima. ocorria mensalmente, por aquele valor fixo, qual a razão de se exigir que o infrator efetue o pagamento de vários meses, possivelmente vários anos ou décadas em regime de antecipação? A vítima, se não tivesse se envolvido no acidente que gerou a lesão não receberia seus salários de forma antecipada, mas sim mês a mês, como ocorre com a quase totalidade da população brasileira.

Outra questão que poderia ser abordada, dentro deste mesmo tópico, diz respeito à possibilidade da norma antes citada incidir. quando vigente o NOVO CÓDIGO CIVIL, aos processos que se encontram em fase de conhecimento, com execução ainda não iniciada.

Embora a Lei de Introdução ao Código Civil preveja, em seu art. $6^{\circ}$, que "a lei em vigor terá efeito imediato e geral, respeitados o ato jurídico perfeito, o direito adquirido e a coisa julgada", e a própria Carta Magna disponha, em seu art. $5^{\circ}$, inciso XXXVI, que "a lei não prejudicará o direito adquirido, o ato jurídico perfeito e a coisa julgada", não faltam exemplos de leis que, ao terem sido editadas, geraram dúvidas várias se poderiam ser aplicadas a processos pendentes.

Apenas para ilustrar, cito a Lei 8.009/90, que regra o instituto do Bem de Família, discutindo-se, daí por diante. se poderia alcançar e desconstituir penhoras feitas no passado, antes da sua vigência, além das Leis que modificaram a sistemática de interposição do agravo de instrumento. fato ocorrido em 1995. Essas Leis trouxeram perplexidade para alguns magistrados, que não sabiam se continuavam a processar aqueles agravos interpostos antes da modificação legislativa ou se deveriam remetê-los de imediato aos Tribunais de Justiça dos Estados.

A matéria vai gerar debates de lado a lado. Antevejo este debate porque vislumbro que a norma enfocada. determinando o pagamento da indenização de uma só vez, é norma de índole processual. Neste caso. não obstante o preceito contido 
no art. $6^{\circ}$ da LICC, e o inciso XXXVI do art. $5^{\circ}$ da Carta Magna, poderia ser cogitada a possibilidade de aplicação do art. 1.211 do Código de Processo Civil, demonstrando que os preceitos processuais, quando editados, aplicam-se "desde logo aos processos pendentes."

Afastando-me dessa primeira observação, indico que as demais modificações operadas pelo NOVO CÓDIGO CIVIL trazem à minha pessoa a idéia de que o novel Código tenta reverter uma situação de muito verificada na matéria de responsabilidade civil.

Todos têm ciência, dispensando alongamento nas colocações, que a jurisprudência é fonte subsidiária em nosso sistema jurídico, originário do sistema romanogermânico; em primeiro lugar, e como fonte primária e principal, aparecendo a lei, situação esta que não se verifica nos países apegados ao sistema Common Law, como Estados Unidos e Inglaterra. Nestes últimos países, no dizer do douto jurista Síl VIO VENOSA, "as decisões dos juízes criam o Direito."

Na matéria de responsabilidade civil desde muito temos subvertido esta ordem, aproximando-nos do sistema do Common Law. É fato incontestável que a responsabilidade civil em nosso sistema jurídico foi completamente desenvolvida a partir de decisões pretorianas, podendo-se dizer que, pelo menos nesta matéria, posiciona-se hoje a jurisprudência como fonte primária do Direito, preterindo-se a lei, ou, melhor explicando, pondo-a em segundo plano.

Esta realidade decorreu do minguado tratamento legislativo dado à questão, talvez porque em 1916, quando editado o Código, não se avolumavam, como ocorre nos dias atuais, os casos de responsabilidade civil, nem em números gerais e nem em variações de tipo.

Gostaria, por derradeiro, de chamar a atenção dos leitores para outras modificações que tratarei an passant, ressaltando, contudo, que as mesmas são extremamente importantes para aqueles que militam com a teoria da responsabilidade civil.

Analisando-se o art. 200 do NOVO CÓDIGO CIVIL BRASILEIRO, percebemos que o mesmo inovou no capítulo relativo à prescrição, para afirmar que se ação se originar de fato que deva ser apurado no juízo criminal, não correrá a prescrição antes da respectiva sentença definitiva."

No sistema atual, e por interpretação do art. 1.525 do Código Civil, percebemos que a vítima de ato ilícito pode ingressar com a demanda civil independentemente do curso da ação penal, haja vista a independência entre as instâncias.

Poderá também a vítima, por escolha sua, aguardar o desfecho da ação penal, e, sendo a sentença ali prolatada de natureza condenatória, ingressar com ação de execução no cível, desprezando o odioso caminho, se assim permitem, do processo de conhecimento, faculdade que se encontra prevista nos arts. 91, inciso I do Código Penal e 584, inciso I do Código de Processo Civil.

No sistema proposto pelo NOVO CÓDIGO CIVIL igual faculdade é dada à vítima, como se conclui pela análise do art. $935^{3}$ da citada Codificação. Mas a

3 "Art. A responsabilidade civil é independente da criminal, não se podendo questionar mais sobre a existência do fato. ou sobre quem seja o seu autor, quando estas questões se acharem decididas no juízo criminal." 
diferença é a de que, na sistemática atual, em se aguardando o desfecho da ação penal, para somente dali ingressar-se com a ação cível, não há suspensão ou interrupção do prazo prescricional, que começa a fluir da data de ocorrência do ato ilícito e do suporte do correspondente prejuízo.

Com o NOVO CÓDIGO CIVIL BRASILEIRO, a fluência do prazo prescricional somente tem início a partir da prolação de sentença definitiva no processo criminal, se o fato agitado no cível houver de ser apurado no crime. Esta inovação legislativa retrata o que alguns Tribunais já vinham decidindo sobre a questão, inclusive o STJ.

Entendo, contudo, que o NOVO CÓDIGO CIVIL apenas faz referência aos fatos QUE DEVAM - no sentido cogente, obrigatório - ser apurados no Juízo Criminal, a meu ver os crimes de iniciativa pública, ou seja, naquelas hipóteses em que o Ministério Público está sujeito ao princípio da obrigatoriedade ou da necessidade, segundo expressão utilizada por alguns doutrinadores da ciência penal ${ }^{4}$.

Em se tratando dos crimes de iniciativa privada, aos quais se aplica o princípio da oportunidade ou conveniência, citando-se como exemplo os crimes contra a honra (art. 145), contra os costumes (art. 225), de fraude à execução (art. 179), todos do Código Penal, entendo que, como a apuração do crime não é obrigatória, dependendo de manifestação volitiva do ofendido, não se aplica o benefício estabelecido no art. 200 do NOVO CÓDIGO CIVIL BRASILEIRO.

Em outras palavras, não pode a vítima confiar-se no aguardo da prolação de sentença definitiva nos autos da ação penal que intentou para, dali, começar a contar o prazo prescricional relativo à ação cível. A prescrição, no meu modesto entender, começa a fluir da data do fato, ou seja, da violação do direito, segundo estatuído no art. 189 do NOVO CÓDIGO CIVIL BRASILEIRO.

E por fim, apenas indico, com constrangimentos, que o art. $206, \S 3^{\circ}$, inciso III do NOVO CÓDIGO CIVIL BRASILEIRO preceitua ser de 03 (três) anos o prazo prescricional para a pretensão de reparação civil, em muito se diminuindo o atual prazo geral, que é de 20 (vinte) anos.

A diminuição radical do prazo parece ser fruto da reivindicação de algumas categorias ou segmentos, como a dos médicos, por exemplo, que reclamam a obrigação de manutenção dos documentos dos pacientes por 20 (vinte) anos, atual prazo prescricional para a propositura de demandas indenizatórias. Lamento a diminuição do prazo, antevendo a possibilidade de vítimas deixarem de pleitear a reparação dada a exigüidade do prazo comentado.

4 Júlio Fabbrini Mirabete, tratando da matéria, esposa a seguinte lição: "O órgão do Ministério Público está sujeito ao princípio da obrigatoriedade (ou da legalidade, ou da necessidade), não ficando a seu arbítrio ou discricionariedade a propositura da ação. Existindo elementos que indiquem a prática de um crime, é ele obrigado a promover a ação penal. Não pode, assim, recusar-se a agir, quando identifique hipótese na qual a lei exige sua atuação; nesse sentido se pode dizer, corretamente, que sua atuação é um dever, seja quando se trate de ajuizar uma ação penal ou civil, seja de interpor um recurso." 
Em relação à prescrição qüinqüenal. aplicada através do Decreto 20.910/32 e incidente sobre as ações de indenização propostas contra o Poder Público, entendo que a mesma será mantida, haja vista tratar-se de legislação especial. embora o art. 205 sinalize que apenas respeita prazos diferenciados. previstos em legislação esparsa. quando menores do que os contidos nos dispositivo enfocado, o que não é o caso.

\section{$3-$ Conclusão}

Tenho para mim a certeza de que o Direito se preserva a intacto por longo tempo, em alguma situações repetindo-se mais adiante aquilo que foi legislado em século anterior. Exemplo disso pode ser extraído da análise do art. 800 da Codificação Imperial que vigia no Brasil até a edição do Código Civil de 1916.

Preceituava o artigo em questão. repito, vigente desde os idos de 1850, que "A indemnisação será sempre a mais completa, que for possível: em caso de dúvida, será a favor do offendido."

A palavra indenização era naquela época escrita com $m n$ e a consoante $s$ onde hoje encontramos o $z$. A palavra ofendido era na época escrita com duas letras $f$.

Mais de cem anos se passaram, mas o princípio ali inserido é o mesmo, pouco importando a mudança da grafia, e o princípio, no dizer do magistral Roque Antônio Carraza. "é uma norma jurídica qualificada".

O princípio visto há cem anos. na legislação do império, no Código de 1916 e graças a Deus no NOVO CÓDIGO CIVIL BRASILEIRO, retrata posiçôes das legislações que concedem benefícios, geralmente processuais, às partes consideradas mais fracas num litígio. hoje em dia denominado de hipossuficientes.

O princípio está no direito penal (in dúbio pro réu), no direito do trabalho (in dúbio pro mísero), no direito do consumidor (in dúbio pro consumidor), e também, em matéria de responsabilidade civil. nos Códigos Civis de todos os tempos, em todos os momentos históricos: in díbio pro vítima.

Confio neste princípio. sabendo que a jurisprudência, aplicando o NOVO CÓDIGO CIVIL, saberá preservá-lo. E é com essa crença que faço minhas as palavras de Montesquieu, rogando a boa vontade de todos na aplicação da codificação analisada. Disse Montesquieu:

Peço uma graça que receio não me seja concedida: de não julgar, pela leitura de um momento, um trabalho de vinte anos, de aprovar ou condenar o livro inteiro e não algumas frases. Se quiser descobrir a intenção do autor, só a poderemos descobrir na intenção da obra."

\section{4 - Referências}

ALVES, Jones Figueiredo e Delgado, Mário Luiz. Noro Código Civil confiontado com o Código Civil de 1916. São Paulo: Editora Método, 2002.

FUX, Luiz. Curso de Direito Processual Civil. São Paulo: Saraiva, 2002. 
MIRABETE, Júlio Fabbrini. Código de Processo Penal interpretado: referências doutrinárias, indicações legais, resenha jurisprudencial: atualizado até dezem. bro de 2000, 8 ed., São Paulo: Atlas, 2001.

MONTENEGRO FILHO, Misael. Ação de Indenização na Prática. Recife: Bagaço, 2002.

NERY JÚNIOR, Nelson. Código de Processo Civil Comentado. $4^{a}$ ed. São Paulo: Revista dos Tribunais, 1999.

STOCO, Rui. Responsabilidade Civil e sua interpretação jurisprudencial. $4^{a}$ ed. São Paulo: Revista dos Tribunais: 1999.

VENOSA, Sílvio de Salvo. Responsabilidade Civil. $2^{\text {a }}$ ed. São Paulo: Atlas, 2002. 


\title{
O Autoritarismo e a Ordem Constitucional no Brasil
}

\author{
José Ribas Vieira
}

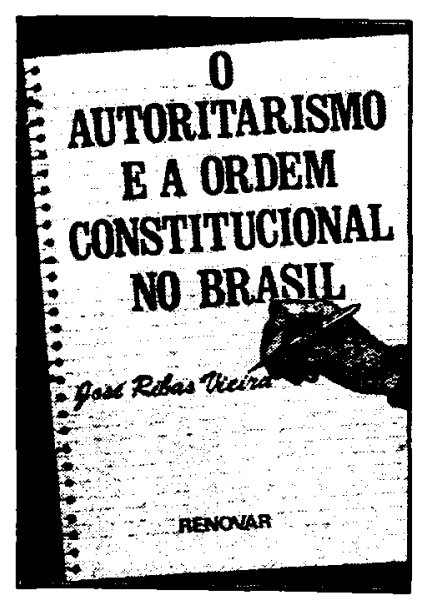

Esta obra assume a postura de falência de um Estado de Direito. A permanente restrição das garantias de direitos individuais e da inexistência de mecanismos de proteçào contra os abusos do poder de Estado no país estimulou o autor a utilizar categorias de Estado de exceção (Marx/Poulantzas) e hegemonia (Gramsci) para interpretar a experiência constitucional brasileira. Este livro serve de instrumento prático de formação e conscientização dos estudiosos do Direito, representando em contraponto as obras tradicionais publicadas no campo da Teoria Geral do Estado/Direito Político no país.

\section{Ref. 0011}

Form. 14x21

Brochura

1988

108 págs.

\section{Obras Completas de Orlando Bitar Estudos de Direito Constitucional e Direito do Trabalho}

Por sua profundidade enudita e por seu alcance crítico no campo da filosofia jurídica e do direito constitucional moderno, Orlando Bitar é um dos mais abalizados e ilustres publicistas deste pais. Logo às primeiras páginas deste admirável trabalho - A Lei Fundamental de Bonn e o Sistema Parlamentar da República Federal Alema - o leitor pressente encontrar-se diante de um espírito percuciente $e$ inquisitivo, que estudou com porfiada aplicação o que de melhor se produziu na Alemanha.

$\begin{array}{lll}\text { Ref. } 0107 & \text { Encadernado } & 1.202 \text { págs. } \\ 2 \text { volumes } & \text { Form. } 16 \times 23 & 1996\end{array}$

Orlando Bitar

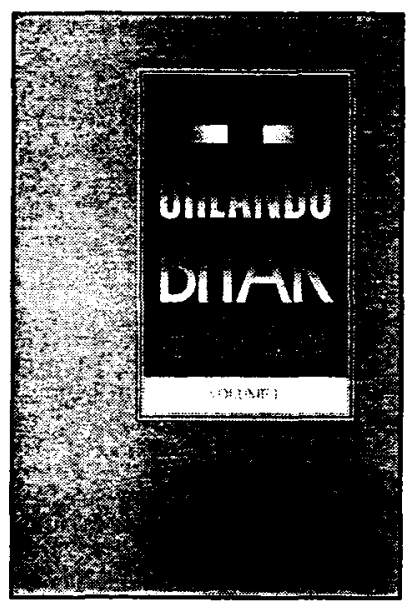

